\title{
Method for the quantitative evaluation of ecosystem services in coastal regions
}

Tomonari Okada ${ }^{\text {Corresp., }}{ }^{1}$, Yugo Mito ${ }^{2}$, Erina Iseri ${ }^{1}$, Toshiyuki Takahashi ${ }^{2}$, Takanori Sugano ${ }^{2}$, Yoshihiro B Akiyama ${ }^{1}$, Kenta Watanabe ${ }^{3}$, Toko Tanaya ${ }^{3}$, Hiroaki Sugino ${ }^{4}$, Kanae Tokunaga ${ }^{5}$, Takahiro Kubo ${ }^{6}$, Tomohiro Kuwae ${ }^{3}$

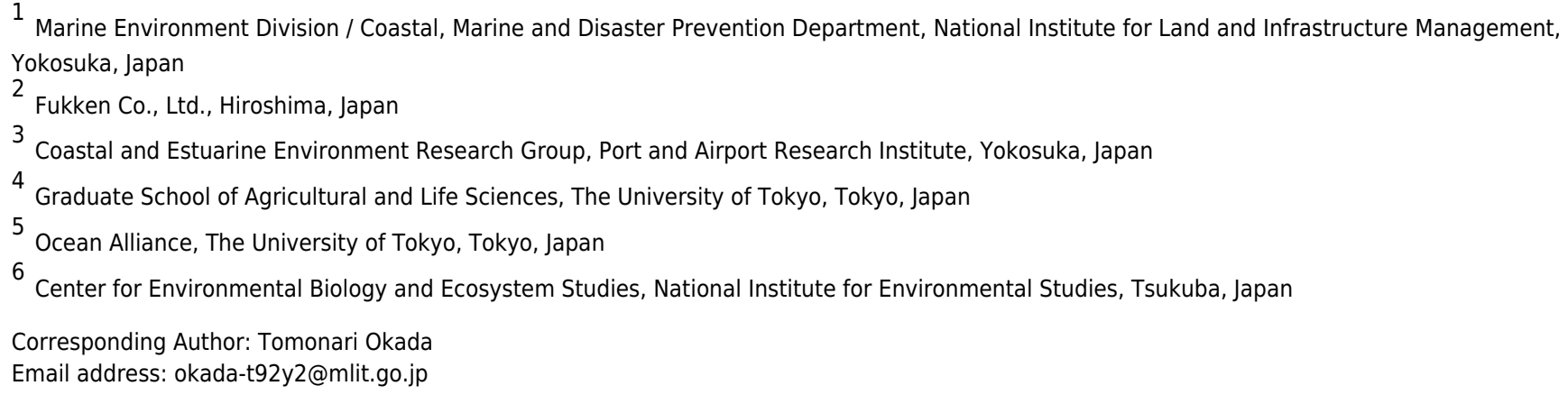

Wetlands, tidal flats, seaweed beds, and coral reefs are valuable not only as habitats for many species, but also as places where people interact with the sea. Unfortunately, these areas have declined in recent years, so environmental improvement projects to conserve and restore them are being carried out across the world. In this study, we propose a method for quantifying ecosystem services that is useful for the proper maintenance and management of artificial tidal flats, a type of environmental improvement project. With this method, a conceptual model of the relationship between each service and related environmental factors in natural and social systems was created, and the relationships between services and environmental factors were clarified. The state of the environmental factors affecting each service was quantified, and the state of those factors was reflected in the evaluation value of the service. As a result, the method can identify which environmental factors need to be improved and if the goal is to increase the value of the targeted tidal flat. The method demonstrates an effective approach in environmental conservation for the restoration and preservation of coastal areas. 
1 Method for the quantitative evaluation of ecosystem services in coastal regions 2

3 Tomonari OKADA ${ }^{1, *}$, Yugo MITO $^{2}$, Erina ISERI ${ }^{1}$, Toshiyuki TAKAHASHI ${ }^{2}$, Takanori

4 SUGANO $^{2}$, Yoshihiro B. AKIYAMA ${ }^{1}$, Kenta WATANABE ${ }^{3}$, Toko TANAYA ${ }^{3}$, Hiroaki

5 SUGINO $^{4}$, Kanae TOKUNAGA ${ }^{5}$, Takahiro KUBO ${ }^{6}$, Tomohiro KUWAE ${ }^{3}$ 6

$7 \quad{ }^{1}$ Marine Environment Division, Coastal, Marine and Disaster Prevention Department, National

8 Institute for Land and Infrastructure Management, 3-1-1 Nagase, Yokosuka, Kanagawa 239-

9 0826, Japan

$10 \quad{ }^{2}$ Fukken Co., Ltd. Hiroshima, 2-10-11 Hikarimachi, Higashi-Ku, Hiroshima 732-0052, Japan

$11{ }^{3}$ Coastal and Estuarine Environment Research Group, Port and Airport Research Institute, 3-1-1

12 Nagase, Yokosuka, Kanagawa 239-0826, Japan

$13{ }^{4}$ Graduate School of Agricultural and Life Sciences, The University of Tokyo, 1-1-1, Yayoi, 14 Bunkyo-ku, Tokyo 113-8657, Japan

$15{ }^{5}$ Ocean Alliance, The University of Tokyo, 7-3-1 Hongo, Bunkyo-ku, Tokyo 113-0033, Japan

$16{ }^{6}$ Center for Environmental Biology and Ecosystem Studies, National Institute for Environmental

17 Studies, 16-2 Onogawa, Tsukuba-City, Ibaraki, 305-8506 Japan

18

$19{ }^{*}$ Corresponding author

20 E-mail: okada-t92y2@mlit.go.jp 


\section{Abstract}

23 Wetlands, tidal flats, seaweed beds, and coral reefs are valuable not only as habitats for many

24 species, but also as places where people interact with the sea. Unfortunately, these areas have

25 declined in recent years, so environmental improvement projects to conserve and restore them

26 are being carried out across the world. In this study, we propose a method for quantifying

27 ecosystem services that is useful for the proper maintenance and management of artificial tidal

28 flats, a type of environmental improvement project. With this method, a conceptual model of the

29 relationship between each service and related environmental factors in natural and social systems

30 was created, and the relationships between services and environmental factors were clarified.

31 The state of the environmental factors affecting each service was quantified, and the state of

32 those factors was reflected in the evaluation value of the service. As a result, the method can

33 identify which environmental factors need to be improved and if the goal is to increase the value

34 of the targeted tidal flat. The method demonstrates an effective approach in environmental

35 conservation for the restoration and preservation of coastal areas. 


\section{Introduction}

39 Evaluating ecosystem services highlights the complexity of the relationship between society and

40 ecosystems and clarifies how human decisions can affect the value of ecosystem services

41 (Millennium Ecosystem Service, 2005). Such evaluations are needed to express any change in

42 value in units (e.g., monetary) that enable the value of ecosystem services to be incorporated into

43 public decision-making processes (Daily, 1997; Mooney, 2005). Because many ecosystem

44 services are mixed with public goods, regulating their use is difficult even when they are nearly

45 or completely exhausted (De Groot et al., 2010). In addition, because many ecosystem services

46 are produced and enjoyed in the absence of market transactions, their value is often

47 underestimated and even ignored in daily decision-making (Pascual, 2010). Furthermore,

48 because many people enjoy the benefits of ecosystem services without even being aware of

49 them, they are often unable to recognize the ecosystem services' value and importance.

For these reasons, demonstrating the values of ecosystems is required and monetization of

51 ecosystem services has been proposed (Costanza et al., 1997; Daily, 1997). Conventional

52 methods to do so include direct market valuation approaches, revealed preference approaches,

53 and stated preference approaches (Farber, Costanza \& Wilson, 2002; Pascual et al., 2010; ).

54 Applying direct market valuation and revealed preference approaches are expected to provide

55 reasonable evaluations of services for which sufficiently developed markets already exist, but not 
56 for services for which no or only nascent markets exist, in which case the use of stated

57 preference approaches is preferred (Chan, Satterfield \& Goldstein, 2012; Cooper et al., 2016).

58 Halpern et al. (2012) proposed the Ocean Health Index (OHI) as a method for

59 comprehensively quantitating ocean health. The OHI defines healthy oceans as those that

60 sustainably deliver a range of benefits to people now and in the future. The index enables the

61 comprehensive evaluation of not only benefits gained from ecosystems but also social and

62 economic benefits (Halpern et al., 2014). The OHI scores the state of each ecosystem service

63 against its reference point (Samhouri et al., 2012), which enables the degree of achievement of

64 each service to be evaluated. The $\mathrm{OHI}$ also enables sustainability and changes in policy or

65 regulatory systems to be considered, and it can be adapted flexibly to match the quantity and

66 quality of data, as well as changes in geographic scale (Elfes et al., 2014; Halpern et al., 2015;

67 Lowndes et al., 2015; Seling et al., 2015). One key advantage of the OHI over other approaches

68 is that it enables the scoring and quantification of services that are difficult to quantify in

69 economic terms.

70 Biodiversity is the foundation for ecosystem services, and the loss of biodiversity causes the

71 value of ecosystem services and productivity to decline (Worm et al., 2006), which is a global

72 issue. In 1992, the Convention on Biological Diversity was adopted as an international

73 framework for comprehensively preserving biodiversity and promoting the sustainable use of 
74 biological resources. Efforts are being made in coastal regions around the world to create

75 artificial wetlands, tidal flats, seaweed beds, and coral reefs with the ultimate goal of restoring

76 and preserving coastal habitats (PIANC, 2008; Fredette and Suedel, 2011; De Vriend and Van

77 Koningsveld, 2012; IADC, 2017). In addition, efforts are also being made to create habitats in

78 harbors by adding habitat functions to port structures such as breakwaters and seawalls

79 (Kamimura et al., 2011).

80 Wetlands, tidal flats, seaweed beds, and coral reefs are valuable places not only as habitat for

81 many species, but also as places where people interact with the sea and access many ecosystem

82 services. Environmental improvement projects for these areas should therefore be evaluated from

83 the perspectives of habitat and ecosystem services. However, these kinds of environmental

84 improvement projects are relatively small in scale when considering ecosystem services, and past

85 evaluation methods of ecosystem services are conducted on large spatial scales (e.g., global,

86 national, regional) and are not suitable for the evaluation of these kinds of environmental

87 improvement projects. In addition, because the evaluation of ecosystem services by

88 environmental economic methods is not linked to either the natural systems or the related social

89 systems of wetlands, tidal flats, seaweed beds, and coral reefs, the need for countermeasures to

90 improve the areas cannot be demonstrated. Moreover, because ecosystems change over time after

91 the creation of an artificial tidal flat or wetland (Palmer, Ambrose \& Poff, 1997; Kuwae, 2005), 
92 the effect of the environmental improvement project must be evaluated for several years

93 following completion. Because the effect of the environmental improvement project strongly

94 depends on ecosystem conditions, it is necessary to carefully consider those conditions to

95 conduct an appropriate evaluation of a project (Zhao et al., 2016). For these reasons, evaluation

96 of environmental improvement projects requires a method that is capable of considering both the

97 relevant natural and social systems and incorporating the concept of sustainability.

98 In response to these problems, we are working on a two-step method in which (1) ecosystem

99 services are scored reliably and (2) a composite evaluation is conducted, taking the weighted

100 service scores into consideration. Including various kinds of environmental improvement

101 projects in the early stages of method development would complicate the process, and artificial

102 tidal flats are being constructed in many coastal regions. Therefore, we initially focused only on

103 tidal flats and quantified the services provided by tidal flats and tidal flat ecosystems.

104 The specific aim of this study, as a first step toward the larger goal, was to develop an

105 evaluation method (Coastal Ecosystem services Index: CEI) that can quantify services and

106 sustainability trends as well as identify relevant environmental factors for each service and those

107 in need of countermeasures by fully considering both the natural systems and social systems in

108 the surrounding area (i.e., waters) of an environmental improvement project. 


\section{Methods}

\section{2.1. Evaluated tidal flats and evaluation year}

112 In this study, we evaluated two artificial tidal flats and two natural tidal flats in Tokyo Bay, an

113 enclosed bay: SN (Shiosai Nagisa) and UK (Umi Koen), the artificial tidal flats, and TR (Tama

114 River tidal flat) and OR (Obitsu River tidal flat), the natural tidal flats (Figs. 1 and 2, Table 1).

115 With this method, the value of a tidal flat is scored by comparison with a reference point (see

116 Section 2.3). Therefore, when evaluating an artificial tidal flat, it is essential to also evaluate the

117 state of a natural tidal flat to be used as the point of reference. It is also necessary to set the target

118 and reference tidal flats within the same overall water area. Although four tidal flats were

119 targeted in this study, it would generally be desirable to use more target tidal flats to reduce the

120 deviation of the service scores.

$121 \mathrm{SN}$ is an artificial biological symbiotic port structure in Tokyo Bay (Figs. 1, 2a) (Morohoshi

122 et al., 2008). To create habitats near the seawall, which has an upright surface, a terrace-type

123 tidal flat was placed in front of the seawall. To create biodiversity in the depth direction, the

124 ground height of the tidal flat was set at three heights $(\mathrm{DL}=0 \mathrm{~m},+0.5 \mathrm{~m},+1.0 \mathrm{~m})$. In addition,

125 this terrace-type tidal flat also serves a disaster-prevention function for the seawall. SN is a

126 demonstration facility, but it is not usually open to the public and access is possible only at

127 events such as environmental education. UK is an artificial tidal flat (Figs. 1, 2b) that was 
128 completed more than 30 years ago. It can be expected that its functions and features are

129 intermediate between natural and artificial tidal flats. It is familiar to residents because it has a

130 public-access beach in a crowded urban area. The other two study areas are natural tidal flats in

131 the bay (Figs. 1, 2c, d).

132 The scope of the tidal flat evaluation comprised the area from the water-land interface to the

133 intertidal zone (i.e., the area shallower than the low water level). The water-land interface was

134 delineated by embankments or structures abutting the landward side of tidal flats.

135 The evaluation year was 2013, with data from 2009 to 2012 being used as past values to

136 calculate the trend scores.

137

138 Table 1. Characteristics of each evaluated tidal flat in this study

Figure 1. Location of the four tidal flats in Tokyo Bay: UK (Umi Koen), SN (Shiosai

141 Nagisa), TR (Tama River tidal flat), and OR (Obitsu River tidal flat)

142

Figure 2. Photos of the four tidal flats: (a) SN, (b) UK, (c) TR, and (d) OR.

144

$145 \quad$ 2.2. Setting of services 
146 Halpern et al. (2012) constructed the OHI, which covered 10 goals encompassing 13 sub- goals

147 from the standpoint of site use: food provision (fishing, mariculture); artisanal fishing

148 opportunities; natural products; carbon storage; coastal protection; coastal livelihoods and

149 economies (jobs, wages, economy); tourism and recreation; sense of place (iconic species,

150 lasting special places); clean waters; and biodiversity (habitats, species). Taking the

151 characteristics of tidal flats into consideration, we constructed an index based on six services (12

152 sub-services): food provision; coastal protection; water front use (recreation, environmental

153 education, research); sense of place (historical designation as special sites, place for everyday

154 rest and relaxation); water quality regulation (removal of suspended matter, organic matter

155 decomposition, carbon storage); and biodiversity (degree of diversity, rare species) (Table 2).

Table 2. Services, indices of services provided, definitions of spatial and temporal range, and key index unit of tidal flats and tidal flat ecosystems. The services and indices are described in more detail in the SI.

\subsection{Calculation method for the service score}

162 To quantify services, we applied the calculation process similar to the one used in OHI. A

163 service score $I_{i}$ for each service $i$ is calculated from the present status $x_{i}$ and the likely near-term 
164 future status $x_{i, \mathrm{~F}}$ with Equation (1):

165

$$
I_{i}=\frac{x_{i}+x_{i, F}}{2}
$$

166 The present status $x_{i}$ is normalized by the reference point with Equation (2):

$$
x_{i}=\frac{X_{i}}{X_{i, R}},
$$

168 where $X_{i}$ is the present status value for service $i$ and $X_{i, \mathrm{R}}$ is the reference point. Any $X_{i}$ value

169 beyond $2 \sigma$ from the mean was determined to be an outlying observation and was not used in the

170 calculations. Halpern et al. (2012) proposed four methods for setting OHI reference points that

171 used: (1) a known functional relationship, (2) a time series approach, (3) a spatial comparison,

172 and (4) an established target value or standard. Because it was difficult to generalize reasonable

173 reference points such as those generated by methods (1) and (4) for specific habitats where

174 conflicts between stakeholders more specifically occur, we used the maximum observed value

175 for each index in the four tidal flats in the most recent 5-year period as the reference point for

176 that index. As described below, this timeframe matches that used to calculate the likely status in

177 the near-term future.

178 Setting reference points to the "best" conditions, as is done in the OHI, may result in an

179 evaluation result that is easy to interpret, but if the reference points are not agreed upon by all

180 stakeholders, it could lead to erroneous information being given to decision-makers. For this

181 reason, CEI does not use reference points based on social consensus; they are set as noted 
182 previously and then used as a relative evaluation criterion. When evaluating a tidal flat service,

183 rather than aiming at a "best" reference point, it is important to evaluate the level of the target

184 tidal flat service compared with that of other tidal flats. With this procedure, it is possible to

185 evaluate the status of the services of the target tidal flats even if the reference point does not

186 represent a "best" condition. Using this type of relative method of setting reference points seems

187 to be the most appropriate in this study, especially because we are comparing artificial and

188 natural tidal flats. In addition, for the purpose of evaluating the status of the artificial tidal flats, it

189 is important to compare them with the status of natural tidal flats in the current ecological

190 environment. Therefore, a period of 5 years was considered to be appropriate in the calculations.

191 On the other hand, if the purpose was to evaluate the status of natural tidal flats in waters where

192 the environment had deteriorated 50 years ago (e.g., in Tokyo Bay), a relative comparison using

193 a maximum value in the past 5 years would not be appropriate. In that case, an ideal value before

194 the environment had deteriorated (i.e., more than 50 years ago) should be used as a reference

195 point.

196 The likely near-term future status $x_{i, \mathrm{~F}}$ for service $i$ is defined by Equation (3):

197

$$
x_{i, F}=\left(1+\beta T_{i}+(1-\beta) P R_{i}\right) \cdot x_{i}
$$

198 where $T_{i}$ is the trend for service $i$ (see Section 2.4), $\beta$ is the relative importance of the trend

199 versus PR (pressure and resilience) scores, and $P R_{i}$ is the PR score for service $i$ (see Section 2.6). 
200 In this study, we used $\beta=0.67$ (Halpern et al., 2012), weighting the directly measured past

201 trend by a factor of 2:1 over the indirectly measured PR scores. However, because our method

202 emphasizes the link between environmental factors and scores, we plan to reconsider the value of

$203 \beta$ in future work.

205 2.4. Calculation of the trend

206 The trend $T_{i}$ ranges from -1.0 to +1.0 and indicates whether the measured values for each service

207 over the most recent 5 years show an upward or downward trend. The trend is derived from the

208 slope of the straight line fit to the relevant time series data. When the trend could not be

209 calculated owing to the absence of data for the past 5 years, it was set to 0 .

210

211 2.5. Sustainability score

212 The difference between the present status $x_{i}$ and likely near-term future status $x_{i, \mathrm{~F}}$ represents the

213 increase or decrease of the service in the next 5 years; this is defined as the sustainability score

$214 S_{i}$ :

215

$$
S_{i}=\frac{\left(x_{i, F}-x_{i}\right)}{x_{i}}
$$

216 A positive sustainability score means that the service will improve under present conditions,

217 and a negative one means that the service will decline under present conditions. We can look for 
218 the environmental factors underlying negative sustainability scores in the PR scores and

219 appropriate countermeasures can be taken for the negative environmental factors.

220

221

2.6. Development of conceptual model and calculation of the pressure and resilience (PR)

scores

223 To obtain useful information for the management of tidal flats, we developed a conceptual model

224 of the natural and social systems considering environmental factors related to a service (Fig. 3,

225 Table 3). This conceptual model is very important in guiding the use of appropriate

226 countermeasures. In addition, environmental factors must be properly selected depending on the

227 target waters.

228

229 Figure 3. Conceptual model of environmental factors for food provision

230

231 Table 3. Environmental factors for food provision

232

233 Here, environmental factors can have a positive effect (enhance resilience) or negative effect

234 (increase pressure) depending on their magnitude or presence/absence. This is where our

235 definitions of pressure and resilience differ from those of Halpern et al. (2012). Using food

236 provision as an example, Halpern et al. (2012) generated separate pressure and resilience scores 
237 based on factors such as fishing and habitat destruction for the former and marine protected and

238 fishing resource management areas for the latter. In this study, we combined pressure and

239 resilience into a single PR score where $P R_{i, j}$ takes a value between -1.0 and 0.0 when the overall

240 effect is negative and between 0.0 and +1.0 when the overall effect is positive; $j$ indicates

241 environmental factor $j$. In addition, the method for evaluating $P R_{i, j}$ differs depending on whether

242 the data being used are quantitative or qualitative.

243 In the case of environmental factors such as dissolved oxygen (DO) concentration and

244 chlorophyll a (Chl-a) concentration for which measured values are available, we set threshold

245 values based on previous research and criteria and calculated $P R_{i, j}$ with evaluation models that

246 would yield a $P R_{i, j}$ of -1.0 when the environmental factor was unfavorable and +1.0 when the

247 environmental factor was favorable.

248 In the case of DO concentration, using the Ministry of the Environment (2016) criterion as a

249 basis, a $P R_{i, j}$ of -1.0 was assigned when the DO concentration was $\leq 2 \mathrm{mg} / \mathrm{L}$ and a $P R_{i, j}$ of +1.0

250 when the DO concentration $\geq 6 \mathrm{mg} / \mathrm{L}$. Intermediate values (between -1.0 and +1.0 ) were assigned

251 for DO concentrations between 2 and 6 mg/L (Fig. 4). Accordingly, DO concentrations $<4 \mathrm{mg} / \mathrm{L}$

252 yielded negative $P R_{i, j}$ and were considered pressures, whereas DO concentrations $>4 \mathrm{mg} / \mathrm{L}$

253 yielded positive $P R_{i, j}$ and were considered resilience factors. 
255 Figure 4. PR score evaluation model for DO concentration

256

257

Other environmental factors such as ground stability and blue tide (Furukawa and Okada,

258

2006) were evaluated from qualitative conditions because it is difficult to quantitatively indicate

a degree for these factors. $P R_{i, j}$ was assigned a score of +0.5 if the positive factor occurred (or

existed) and a score of -0.5 if the negative factor occurred (or existed). Because the impacts of

such environmental factors vary in magnitude, it would be ideal to assign scores ranging between

262

-1.0 and +1.0 depending on the degree of impact. However, there are insufficient data and

knowledge to be able to quantitatively differentiate impacts. Accordingly, in this study, the

influence of uncertain environmental factors on the scores was assumed to be half that of certain

environmental factors, and we assigned either -0.5 or +0.5 for these factors.

$P R_{i}$ represents the average of all $P R_{i, j}$ scores impacting service $i$. Although the weights of

each environmental factor were assumed to be the same in this study, we plan to study the

weighting of the influence of environmental factors on services in the future.

\subsection{Setting of indices}

271 For each service, we identified indices that accurately represent the state of the service being

272 assessed and for which data are available (Table 2). 
274 evaluate the supply capacity of commercially important species. Details are shown in the

275 Supplemental Information (SI 1). As indicators of coastal protection, we used the wave energy

276 reduction ratio and the wave run-up height ratio to evaluate an area's flood prevention function

277 through the reduction of wave surges and wave overtopping (SI 2).

278 As an index of recreation for water front use, we used the number of visitors for the purpose

279 of recreation and evaluated the use of tidal flats for shellfish gathering and other activities (SI 3).

280 As an index of environmental education for water front use, we used the number of visitors for

281 the purpose of environmental education and related activities (SI 4). As an index of research for

282 water front use, we used the number of published papers and reports (SI 5).

283 As an index of historical designation as special sites for sense of place, we used the numbers

284 of festivals and of faith-related buildings (SI 6). As an index of places for everyday rest and

285 relaxation for sense of place, we developed a rest and relaxation index relative to the total hours

286 of everyday use that was adjusted for the user's stated level of conscious awareness of the value

287 of the sites for walks, rest and relaxation, and other similar uses (SI 7).

288 As an index of suspended material removal for water quality regulation, we used the bivalve

289 water filtration volume (SI 8). As an index of organic matter decomposition for water quality

290 regulation, we used the COD purification amount (calculated from the production/biomass ratio) 
291 by benthic organisms (SI 9). As an index of carbon storage for water quality regulation, we used

292 the carbon fixation in benthic organisms and sediment (0-10 $\mathrm{cm}$ in depth) (SI 10).

293 As an index of degree of diversity for biological diversity, we used the Shannon-Wiener

294 diversity index $\left(H^{\prime}\right)$ for the entire study area (SI 11). Finally, as an index of rare species for

295 biological diversity, we used the number of threatened species adjusted by category of threatened

296 status (SI 12).

\subsection{Spatial scale and time scale}

299 There are two approaches to the spatial scale in calculating services: evaluate either the amount

300 of service obtained from the entire tidal flat or the amount of service obtained from a unit area.

301 The first type of evaluation result is obviously highly dependent on the area of the tidal flat. The

302 second type does not demonstrate the total amount of service, but it does show the quality of the

303 tidal flat.

304 For these reasons, CEI basically uses values per unit area. However, indices with weak

305 dependency on area and those that are difficult to correct for phenomena per unit area were based

306 on the amount of service obtained from the entire tidal flat (Table 2). The number of species has

307 a nonlinear relationship with area (Gotelli and Colwell, 2001), and it is difficult to formulate a

308 relation. Therefore, with regard to the number of species, the survey results were used without 
309 spatial correction. When evaluating biodiversity, we used data on the number of species obtained

310 by the same survey method to reduce bias caused by a difference in the number of survey sites

311 between tidal flats as much as possible. Introducing an appropriate method for spatial correction

312 of the number of species remains to be dealt with in the future.

313 The time scale was set to 1 year. However, because the time correction method depends on

314 the characteristics of the index, it differs for each indicator (Table 2). An annual average value

315 was used as the index value for an index where the annual average value is important, such as the

316 existing number of clams or amount of carbon storage. For an index where annual total is

317 important, such as the number of visitors and rare species, the annual total value was used as the

318 index value. For an index where the annual maximum value is important, such as the relative

319 wave run-up height for coastal protection, the annual maximum value was used as the index

320 value.

\section{3. Results}

323 The service scores are summarized in Table 4. Details of the calculation process and more

324 detailed results for each area are presented in the SI. Because the same reference point was used

325 for all four tidal flats when quantifying progress toward each service, it is possible to compare

326 service scores across tidal flats. In addition, for each service, areas in need of countermeasures 
327 and where they could prove effective can be identified from the sustainability scores and PR

328 scores of the environmental factors.

329

330 Table 4. Calculated service and sustainability scores for all services. Gray shading

331 highlights a negative sustainable index score.

332

333 3.1. Food provision

334 The food provision service score of SN (12.4) was higher than those of the natural tidal flats

335 (TR, 4.0, and OR, 5.6), indicating a higher quality (wet weight per unit area) (Table 4, SI 1).

336 Although SN had a high service score, its sustainability score was negative (-41\%), indicating

337 that this service will decay under the present condition. To suppress this decay, countermeasures

338 need to be taken in the categories of anoxic water, blue tide, ground stability, predatory or

339 competitive species, and protection of species, all of which had negative PR scores (Fig. S3).

340 Although the service score of UK was low (5.3), its sustainability score was positive $(+17 \%)$, so

341 the present status can be maintained in the present environmental condition. UK is located in an

342 area with good water quality and has been established for more than 30 years, so there is no need

343 for countermeasures against the water environment and instability of the ground just after

344 construction. The service scores of TR and OR (4.0 and 5.6) were not high, but the sustainability 
345 scores were positive $(+1 \%$ and $+12 \%$ ) (Table 4$)$, so their present status can be maintained in the

346 present environmental condition. To improve the service of TR, attention could be paid to

347 predatory or competitive species (Fig. S3), and in OR, anoxic waters should be a point of

348 attention.

349

350

\subsection{Coastal protection}

351 Coastal protection was evaluated from two indicators, the maintenance effect of tidal flats owing

352

to wave energy reduction and the suppression effect of wave run-up height by a seawall behind

tidal flats (SI 2). The maintenance effect of tidal flats owing to wave attenuation was strong in

354 large tidal flats, but the difference between the artificial tidal flats was small because the artificial tidal flats were basically arranged in waters with small waves (Table S5). There was little difference in the suppression service score, most likely because it had been thoroughly investigated at the design stage of the seawall (Table S6). In other words, the artificial tidal flat and the seawall are designed to satisfy the function of coastal protection. From this point of view, we consider the sustainability score to be more important in this category than the service score

360 (Table 4). The sustainability scores of SN and UK, the artificial tidal flats, were not negative

$361(0 \%,+13 \%)$, and countermeasures are therefore considered to be unnecessary. The sustainability

362 score of TR was negative ( $-4 \%)$, mainly because management of ground condition and 
363 inspection and repair of seawall have not been implemented (Fig. S7).

\section{3.3. Recreation (water front use)}

366 Because $\mathrm{SN}$ is within a demonstration area that is not open to the public, recreation is not

367 allowed and, therefore, there is no service score for this category. Because UK is used by many

368 people, its service score was extremely high (78.7), but the service scores of the other tidal flats

369 were less than 1 point (Table 4, SI 3). However, deterioration in the habitat (such as a massive

370 growth of sea lettuce, Ulva sp.) was observed (Fig. S9), so there is concern that the sustainability

371 score was negative $(-1 \%)$. The sustainability score of TR was also negative $(-4 \%)$. To maintain

372 or enhance the present status of Recreation in the natural tidal flats, the factors management

373 group, attracting visitors, publicity work, incidental facilities, and accessibility need attention

374 (Fig. S9). However, for natural tidal flats, stakeholders need to be consulted when deciding

375 whether promotion of recreation is appropriate because there may be trade-offs involved. The

376 trade-off relationships between these services should be examined in future research.

\section{3.4. Environmental education (water front use)}

379 The service scores of environmental education for SN and UK (40.3 and 66.8) were higher than

380 those of the natural tidal flats (Table 4, SI 4). However, the sustainability score of SN was 
381 negative $(-41 \%)$. The factors attracting visitors, publicity work, accessibility, protection of

382 species, healthy habitat, and stability of ground were indicated as needing improvement to

383 maintain the service of environmental education (Fig. S11). At TR, no environmental education

384 was carried out and the service score was 0 , in large part because there is no organization such as

385 a non-profit organization to implement a relevant program. The service score of OR (39.4) was

386 similar to that of SN, and its sustainability score was also high $(+17 \%)$, indicating that

387 environmental education is active in this area and the condition of the surrounding environment

388 is also good.

389

390 3.5. Research (water front use)

391 The natural tidal flats, TR and OR, had higher service scores (75.1 and 70.8) for research than

392 the artificial tidal flats (Table 4, SI 5). As natural scientific research subjects, natural tidal flats

393 may be more attractive. At the demonstration facility SN, regular testing and surveillance were

394 conducted, and the service score was close to that of the natural tidal flats (64.7). Because

395 research is established with various interests and purposes, its PR index was not evaluated. For

396 this reason, the sustainability scores only show only recent trends and have little meaning when

397 considering countermeasures. 
399 3.6. Historical designation as special sites (sense of place)

400 Because this service is unique to the given area, it does not exist in artificial tidal flats, which

401 have no cultural history and have usage constraints as public facilities (Table 4, SI 6). However,

402 it is possible that this service may exist in an artificial tidal flat that was created as a mitigation

403 of a natural tidal flat that had the service.

404

405 3.7. Places for everyday rest and relaxation (sense of place)

406 Because $\mathrm{SN}$ is within an experimental area that is not open to public, this service is restricted,

407 similar to recreation (Table 4, SI 7). On the other hand, UK is used by many people and its

408 service score was extremely high (100). The sustainability score was also positive $(+10 \%)$, so the

409 area can continue to provide a high level of service under present environmental conditions.

410 Among the PR indexes, only the healthy habitat factor was negative (Fig. S19). By implementing

411 countermeasures related to this factor, it could be possible to provide an even higher level of

412 service. The service scores of TR and OR, the natural tidal flats, were low (3.2 and 2.8). The

413 sustainability score of TR was negative $(-3 \%)$, and the factors management of ground condition,

414 management groups, and incidental facilities were indicated as needing countermeasures. The

415 OR sustainability score was positive $(+17 \%)$, so the present status can be maintained under

416 present environmental conditions. The low service score was likely influenced by the small 
417 number of people living in the surrounding area.

418

419 3.8. Suspended material removal (water quality)

420 The SN service score was high (100) for material removal (Table 4, SI 8). In addition, its

421 sustainability score was positive $(+18 \%)$. Although the present environmental condition is

422 sufficient, countermeasures against anoxic water, blue tide, and stability of ground would be

423 effective to enhance the service (Fig. S22). The UK service score (20.7) was not as high that of

424 SN, but its sustainability score $(+13 \%)$ and PR index were high and it is expected to maintain a

425 stable service. The service scores of both natural tidal flats were not as high (14.3 and 8.9 for TR

426 and OR, respectively), but both had positive sustainability scores $(+9 \%$ and $+10 \%)$, so a stable

427 level of service can be expected.

428

429 3.9. Organic matter decomposition (water quality)

430 Although this SN service score was high (52.1), the sustainability score was negative (-8\%)

431 (Table 4, SI 9). To maintain this service, countermeasures for anoxic water, blue tide, and

432 stability of ground should be considered (Fig. S24). In contrast, the UK service score was low

433 (20.7), but the sustainability score was positive (+13\%). The TR service score (40.2) was high

434 and its sustainability score was positive $(+22 \%)$, so a stable level of service can be expected. 
435 Although the service score of OR (17.8) was not as high as that of TR, the sustainability score

436 was positive $(+19 \%)$, so stable service can be expected to be maintained.

437

438 3.10. Carbon storage (water quality)

439 The service score of SN (58.7) was high, but the sustainability score was negative (-9\%) (Table

4404 , SI 10) because the trend index had a large negative value (Table S36). To enhance the carbon

441 storage service, it is important to increase the amount of carbon stored in the bottom sediment,

442 which is responsible for about $90 \%$ of the carbon storage function, and it is necessary to take

443 countermeasures related to ground stability (Fig. S27). The service score of UK (16.6) was low

444 and its sustainability score was negative $(-3)$. To enhance its carbon storage service, the

445 accumulation of organic matter in sediment by sand cupping should be promoted. The service

446 score of TR (79.7) was high, but its sustainability score was negative (-8\%). Although the

447 service score of OR (13.6) was low, its sustainability score was positive $(+3 \%)$, indicating it is

448 expected to maintain a low but stable level of service.

\section{3.11. Degree of diversity (biodiversity)}

451 The service scores of both SN and UK (86.5 and 100) were equal to or higher than those of the

452 natural tidal flats, and the sustainability scores of both were positive $(+10 \%$ and $+28 \%)$ (Table 4 , 
453 SI 11). The PR index of SN was negative (Table S39), however, and it would be desirable to pay

454 attention to the factors alien species, surrounding environment, stability of ground, and

455 protection of species (Fig. S29). The service scores of TR and OR (87.9 and 78.1) were also

456 high, but the sustainability score of TR was negative (-2\%). To maintain this high level of

457 service, it is necessary to pay particular attention to alien species and protection of species.

458

459

\subsection{Rare species (biodiversity)}

460

The service scores of SN and UK (7.8 and 12.0) were lower than those of TR and OR (Table 4,

461 SI 12). It is probably inevitable that the rare species service would be lower in artificial tidal flats

462 as compared with natural tidal flats. However, to at least approach the service level of natural

463 tidal flats, important factors are predatory or competitive species, alien species, healthy habitat,

464 stability of ground, and protection of species in SN and alien species and healthy habitat in UK

465 (Fig. S31).

466

467 4. Discussion

468 4.1. Characteristics and features of the method

469 By comparing the service scores among multiple tidal flats, we were able to evaluate the service

470 of each tidal flat. By combining the service scores with a sustainability score, it was possible to 
471 evaluate whether the service was sustainable or deteriorating under present environmental

472 conditions. If the level of service was low or there was concern about service deterioration, we

473 could use the PR scores to identify the relevant environmental factor(s) for which it would be

474 desirable to implement countermeasures. Of course, whether this environmental factor is valid or

475 not depends on whether the conceptual model has been properly designed and implemented. At a

476 later practical stage, it will be necessary to review the conceptual model. Incidentally, the

477 conceptual model shown in this study is a model for tidal flats in Tokyo Bay, which has

478 undergone remarkable eutrophication. It is important to create a conceptual model that is

479 appropriately based on the characteristics of the applicable water area.

480 For the artificial tidal flat SN, the sustainability scores of food provision, environmental

481 education, organic matter decomposition, carbon storage, and rare species were negative,

482 indicating these services needed countermeasures to become sustainable. Environmental factors

483 identified as requiring countermeasures were anoxic water, blue tide, stability of ground,

484 predatory or competitive species, protection of species, attracting visitors, publicity work,

485 accessibility, healthy habitat, and alien species. Among these, ground stability was a common

486 environmental factor identified for all services, and anoxic water and blue tide were common

487 environmental factors in need of countermeasures for food provision, organic matter

488 decomposition, and carbon storage. It is therefore clear that some environmental factors are 
489 applicable to multiple services.

490 At this stage, the relative "weight" of service has not been considered. In other words, the

491 value of 100 points differs depending on the service, and it is impossible to compare values

492 between services using only the values presented in Table 4. Also, it is not possible to simply

493 integrate the service scores and give a total score within a tidal flat. Therefore, at this stage, it is

494 unknown which countermeasures will effectively improve the overall level of service of the tidal

495 flat. When considering the use of countermeasures, it is necessary to consider which ones will be most effective based on the contribution of relevant environmental factors to multiple services

497 and a comprehensive evaluation of services.

498 Regarding such a comprehensive evaluation, Halpern et al. (2012) assumed that all services

499 had the same weight, and the average score of all services was taken as a total score. In addition,

500 Daigle et al. (2017) calculated an overall score by setting service weights based on the

501 importance of each service obtained from the results of a questionnaire administered to residents

502 in the target evaluation area. In response to this problem, we are considering a weight-setting

503 method based on economic value and questionnaire survey results.

504 As mentioned in Section 3.3 (recreation), there may be a trade-off between services. Too

505 little information was obtained from these four tidal flats to show any trade-off relationships. It is

506 therefore necessary to clarify any trade-offs by increasing the number of study areas. Currently, 
507 our results allow consideration of countermeasures to improve individual services, but that is not

508 sufficient to improve the comprehensive evaluation of services of tidal flats. Incorporating trade-

509 off relationships and a weighting of services is necessary to be able to consider which services

510 would be most effective for taking countermeasures.

511 It is conceivable that the weight of the effect of the environmental factors also differs. At

512 present, the PR scores were all weighted the same, but we need to consider weighting these

513 scores as well. In addition, we assumed a qualitative PR score to be half that of a quantitative PR

514 score. This assumption should be evaluated together with the weighting of scores within the PR

515 index. Finally, the coefficient $\beta$, which determines the contribution rate of the PR index to the

516 near-term future value, was set at 0.67 according to Halpern et al. (2012), but an appropriate

517 value that emphasizes the link between environmental factors and service scores should be

518 considered.

519 The indicators of each service were limited to environmental investigation indices that have

520 been generally implemented in Japan. For this reason, from a scientific point of view, some of

521 these may be inappropriate indices or models. For example, use of the carbon storage rate as an

522 index of carbon storage is adequate if it is to evaluate the mitigation effect of global warming,

523 but it is limited in that it is based on the existing carbon storage amount as an indicator. In

524 addition, because the number of species used in the evaluation of diversity depends largely on 
525 the number of survey sites, a correction model must be implemented for the number of survey

526 sites to eliminate any bias. However, some insufficiency in these types of indicators cannot be

527 avoided in any model owing to data constraints, lack of scientific knowledge, and other similar

528 factors. Recognizing the insufficiency of data and models, nevertheless, we should still work to

529 improve them to the extent possible (Lowndes et al., 2015).

530

531 4.2. Range of error in scores

532 Trend scores were evaluated based on the slope of the trajectory of the present status scores over

533 the most recent 5 years. As such, differences in slope estimations are reflected in likely near-term

534 future status and service scores. The 95\% confidence intervals (CI) for likely near-term future

535 status obtained by performing linear regression increase the further one moves away from the

536 data used to make the estimate. This occurs because the slopes and intercepts of estimated

537 regression lines have associated variances that are compounded over time. For this reason, we

538 constructed $95 \%$ CIs for trend scores based on the standard errors of the slopes of the regression

539 lines. Multiplying this value by 5 (representing the years) yields the $95 \%$ CIs for the trend scores.

540 The $95 \%$ CI based on standard error can easily be estimated by multiplying the standard error by

5413 (3 degrees of freedom, 95\% confidence limits for a two-tailed $t$-distribution). The following

542 equations were used: 
543

544

545

546

547

548

549

550

551

552

553

554

555

556

557

558

559

$$
T_{i}=5 \cdot t_{i}
$$

$$
T_{i-U}=5 \cdot T_{i}+5 \cdot 3 s e_{i}
$$

$$
T_{i-L}=5 \cdot T_{i}-5 \cdot 3 s e_{i}
$$

where $T_{i}$ is the trend score, $T_{i-U}$ is the upper limit of the $95 \% \mathrm{CI}, T_{i-L}$ is the lower limit of the $95 \%$

$\mathrm{CI}, t_{i}$ is the slope of the regression line, and $s e_{i}$ is the standard error of the slope.

We estimated CIs for likely near-term future status and service scores for food provision, coastal protection, environmental education, research, suspended material removal, organic matter decomposition, carbon storage, degree of diversity, and rare species for which likely nearterm future status were calculated based on past data (Fig. 5). The other services (recreation, historical designation as special sites, and places for everyday rest and relaxation) were not included because there was no past data and trends were not estimated.

For food provision, suspended material removal, organic matter decomposition, and degree of diversity, whose service scores depend on biomass, the error was large in SN. It has been less than 10 years since SN was constructed, and biomass in the area may still be in transition. In addition, $\mathrm{SN}$ is located in a port with poor water quality, and environmental impacts such as anoxic water and blue tide often occur and the habitat environment is unstable. In contrast, the error for rare species was greater for the natural tidal flats. This occurred because, in the natural tidal flats, the annual differences in the number of rare species observed was large, whereas in 
561 the artificial tidal flats, few rare species were observed in all years so the data were stable from

562 year to year.

563 Although there were services with a deviation of about \pm 20 , the average deviation was less

564 than \pm 10 . Some of the variation is likely the result of annual changes reflected in the survey

565 data.

566

567 Figure 5. Ranges of error in (A) - (I) trend scores, (J) - (R) likely near-term future status,

and (S) - (AA) service scores for food provision, coastal protection, environmental

569

education, research, suspended material removal, organic matter decomposition, carbon

570

storage, degree of diversity, and rare species

571

572

\section{Conclusions}

573 In this study, we developed a method that can properly quantify services and identify

574 environmental factors to improve services by fully considering the ecosystem of the surrounding waters of four artificial and natural tidal flats. To appropriately reflect the ecological conditions of the surrounding waters in the evaluation results of an environmental improvement project, it is important to create a conceptual model that includes the characteristics of the surrounding waters. The developed method is capable of creating a set of scores for the environmental factors 
579 that affect each service. Therefore, it is possible to better understand priority factors for

580 improving the area and the environmental factors for which countermeasures would be effective,

581 all of which can be utilized for more efficient management. However, there are several problems

582 at this stage in the method development, as noted in the discussion. As future work, we hope to

583 address these problems and create an even more practical evaluation method.

584

585 
586

587

588

589

590

591

592

593

594

595

596

597

598

599

600

601

602

603

604

605

606

607

608

609

610

611

612

613

614

615

616

617

618

619

620

621

\section{References}

Chan, K., Satterfield, T., Goldstein, J. 2012. Rethinking ecosystem services to better address and navigate cultural values. Ecol. Econ. 74:8-18; DOI 10.1016/j.ecolecon.2011.11.011.

Cooper, N., Brady, E., Steen, H. \& Bryce, R. 2016. Aesthetic and spiritual values of ecosystems: Recognising the ontological and axiological plurality of cultural ecosystem 'services'. Ecosyst. Serv. 21:218-229; DOI 10.1016/j.ecoser.2016.07.014.

Costanza, R., dArge, R., Groot, R., Farber, S., Grasso, M., Hannon, B., Limburg, K., Naeem, S., Oneill, R. V., Paruelo, J., Raskin, R. G., Sutton, P. and van de Belt, M. 1997. The value of the world's ecosystem services and natural capital. Nature 387:253-260.

Daigle RM., Archambault P., Halpern BS., Lowndes JSS., Côté IM. 2017. Incorporating public priorities in the Ocean Health Index: Canada as a case study. PLoS ONE 12: e178044. DOI: 10.1371/journal.pone.0178044.

Daily, G. C. 1997. Nature's Services: Societal Dependence on Natural Ecosystems. Island Press: pp. 49-69.

De Groot, R, Fisher, B., Christie, M., Aronson, J., Braat, L., Gowdy, J., Haines-Young, R., Maltby, E., Neuville, A., Polasky, S., Portela, R. and Ring, I. 2010. Chapter1 Integrating the ecological and economic dimensions in biodiversity and ecosystem service valuation, in: The Economics of Ecosystems and Biodiversity, The Ecological and Economic Foundations. DOI: $10.4324 / 9781849775489$.

De Vriend, H.J. and Van Koningsveld, M. 2012. Building with Nature: Thinking, Acting and Interacting Differently, EcoShape, Dordrecht, the Netherlands.

Elfes, CT., Longo, C., Halpern, BS., Hardy, D., Scarborough, C., Best, BD., Pinheiro, T., Dutra, GF. 2014. A regional-scale ocean health index for Brazil. PLoS ONE 9:e92589 DOI 10.1371/jour-nal.pone.0092589.

Farber SC., Costanza R., Wilson MA. 2002. Economic and ecological concepts for valuing ecosystem services. Ecological Economics 41:375-392. DOI: 10.1016/S09218009(02)00088-5.

Fredette, T.J. and Suedel, B.C. 2011. Corps of Engineers Aims for Environmental Sustainability, Inland Port, 6:4-7.

Furukawa, K. and Okada, T. 2006. Tokyo Bay: its environmental status - past, present and future -, in: E. Wolanski (Ed.), The Environment in Asia Pacific Harbors, Springer, pp. 15-34.

Gotelli, NJ., Colwell, RK. 2001. Quantifying biodiversity: procedures and pitfalls in the measurment and comparison of species richness. Ecology Letters 4:379-391. DOI: 10.1046/j.1461-0248.2001.00230.x.

Halpern BS, Longo C., Hardy D., McLeod KL., Samhouri JF., Katona SK., Kleisner K., Lester SE., O’Leary J., Ranelletti M., Rosenberg AA., Scarborough C., Selig ER., Best BD., 
622

623

624

625

626

627

628

629

630

631

632

633

634

635

636

637

638

639

640

641

642

643

644

645

646

647

648

649

650

651

652

653

654

655

656

657

Brumbaugh DR., Chapin FS., Crowder LB., Daly KL., Doney SC., Elfes C., Fogarty MJ., Gaines SD., Jacobsen KI., Karrer LB., Leslie HM., Neeley E., Pauly D., Polasky S., Ris B., St Martin K., Stone GS., Sumaila UR., Zeller D. 2012. An index to assess the health and benefits of the global ocean. Nature 488:615-620. DOI: 10.1038/nature11397.

Halpern, BS., Longo, C., Scarborough, C., Hardy, D., Best, BD., Doney, SC., Katona, SK., Mcleod, KL., Rosenberg, AA., Samhouri, JF. 2014. Assessing the health of the US West coast with a regional-scale application of the ocean health index. PLoS ONE 9:e98995. DOI 10.1371/journal.pone.0098995.

Halpern BS., Longo C., Stewart Lowndes JS., Best BD., Frazier M., Katona SK., Kleisner KM., Rosenberg AA., Scarborough C., Selig ER. 2015. Patterns and emerging trends in global ocean health. PLoS ONE 10: e0117863. DOI: 10.1371/journal.pone.0117863.

International Association of Dredging Companies (IADC). 2017. Facts about Building with Nature, IADC Information Update from the IADC. https://www.iadc-

dredging.com/ul/cms/fck-uploaded/documents/PDF\%20Facts\%20About/facts-aboutbuilding-with-nature.pdf (January, 2018)

Kamimura, S., Yoshida, J., Okada, T., Furukawa, K. 2011. Monitoring of the ecological-type revetment on Port of Akita, Japan: A first year report, Technical Note of NILIM, 648. http://www.nilim.go.jp/lab/bcg/siryou/tnn/tnn0648pdf/ks0648.pdf (September, 2018)

Kuwae, T. 2005. Development and self-stabilization of restored and created intertidal flat ecosystems. Journal of JSCE 790:25-34; DOI 10.2208/jscej.2005.790_25.

Lowndes, JSS., Pacheco, EJ., Best, BD., Scarborough, C., Longo, C., Katona, SK., Halpern, BS. 2015. Best practices for assessing ocean health in multiple contexts using tailorable frameworks. PeerJ 3:e1503; DOI 10.7717/peerj.1503

Millennium Ecosystem Assesment (MEA). 2005. Ecosystem and Human Well Being: Snthesis. Island Press.

Ministry of the Environment. 2016. Notification revision related to addition of environmental criteria to water pollution. https://www.env.go.jp/press/102287.html. (January, 2018)

Mooney, H. 2005. Confronting the human dilemma: How can ecosystems provide sustainable services to benefit society?, Nature, 434:561-562. DOI:10.1038/434561a

Morohoshi, K., Suzuki, N., Imamura, H., Kameyama, Y., Kimura, T. 2008. Project planning of the restoration, utilization, and disaster prevention function. Journal of Japan Society of Civil Engineers, Ocean Engineering 24:759-764. DOI: https://doi.org/10.2208/prooe.24.759

Palmer MA., Ambrose RF., Poff NLR. 1997. Ecological Theory and Community Restoration Ecology. Restoration Ecology 5:291-300. DOI: 10.1046/j.1526-100X.1997.00543.x. Pascual U., Muradian R., Brander L., Christie M., Cornelissen H., Eppink F., Farley J., Loomis J., Pearson L., Perrings C., Polasky S. 2010. Chapter 5 The economics of valuing ecosystem 
658 services and biodiversity, in: The Economics of Ecosystems and Biodiversity, Ecological and 659 economic foundations:183-255. DOI: 10.4324/9781849775489.

660 PIANC. 2008. Working with Nature PIANC Position Paper, PIANC, Brussels, Belgium.

661 Samhouri, JF., Lester, SE., Selig, ER., Halpern, BS., Fogarty, MJ., Longo, C., Mcleod, KL.

662 2012. Sea sick? Setting targets to assess ocean health and ecosystem services. Ecosphere

663 3:art41

664 Selig ER., Frazier M., O’Leary JK., Jupiter SD., Halpern BS., Longo C., Kleisner KL., Sivo L.,

665 Ranelletti M. 2015. Measuring indicators of ocean health for an island nation: The ocean

666 health index for Fiji. Ecosystem Services 16:403-412. DOI: 10.1016/j.ecoser.2014.11.007.

667 Worm, B., Barbier, E. B., Beaumont, N., Duffy, E., Folke, C., Halpern, B. S., Jackson, B. C.

668 Lotze, HK., Micheli, F., Palumbi, SR., Sala, E., Selkoe, KA., Stachowicz, JJ. and Watson, R.

669 2006. Impacts of biodiversity loss on ocean ecosystem services. Science, 314:787-790.

670 Zhao Q., Bai J., Huang L., Gu B., Lu Q., Gao Z. 2016. A review of methodologies and success

671 indicators for coastal wetland restoration. Ecological Indicators 60:442-452. DOI:

$672 \quad 10.1016 /$ j.ecolind.2015.07.00.

673 


\section{Figure 1 (on next page)}

Location of the four tidal flats in Tokyo Bay: UK (Umi Koen), SN (Shiosai Nagisa), TR (Tama River tidal flat), and OR (Obitsu River tidal flat) 


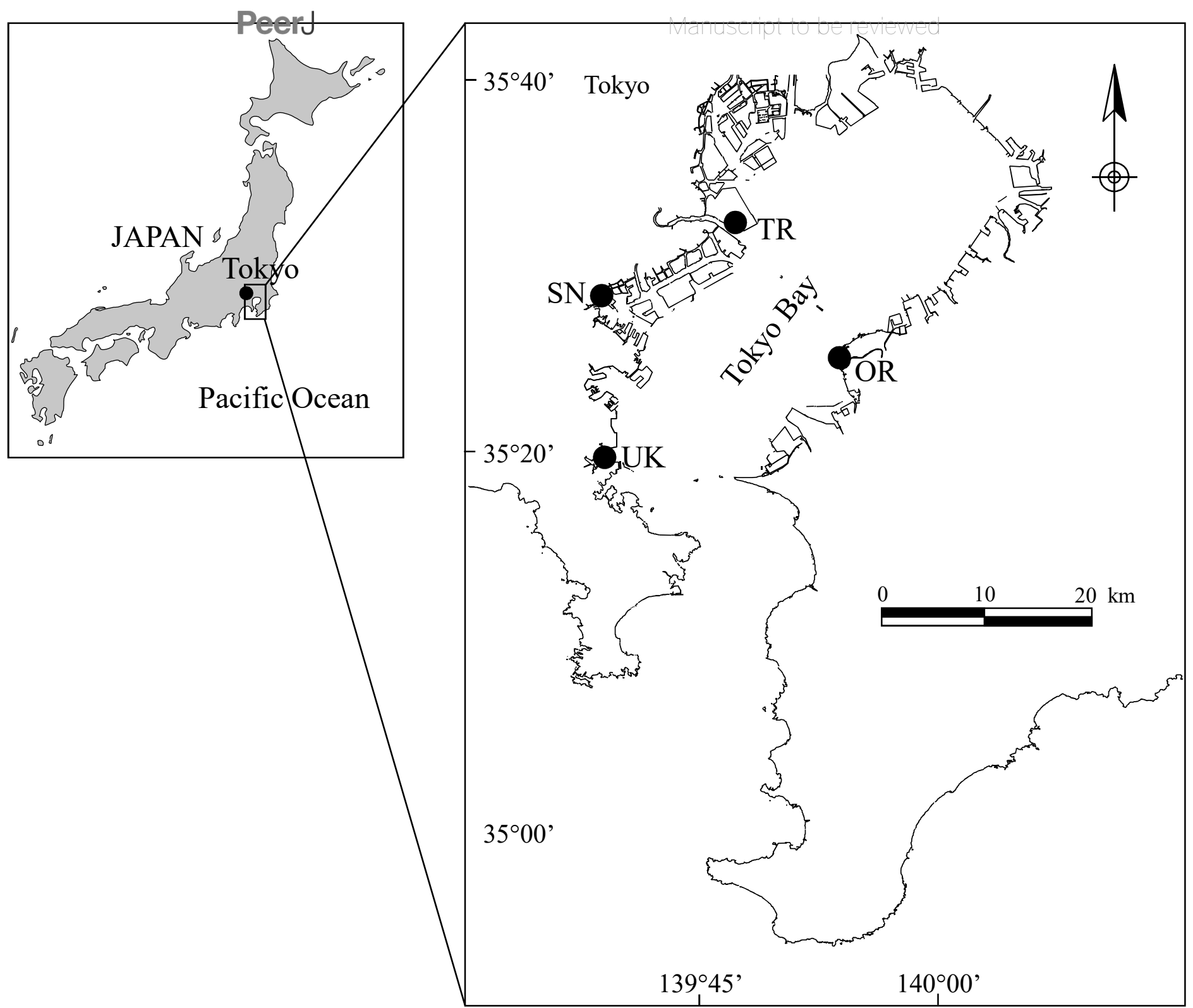




\section{Figure 2}

Photos of the four tidal flats: (a) SN, (b) UK, (c) TR, and (d) OR.

(d) source: aerial photograph of Geospatial Information Authority of Japan, https://mapps.gsi.go.jp/
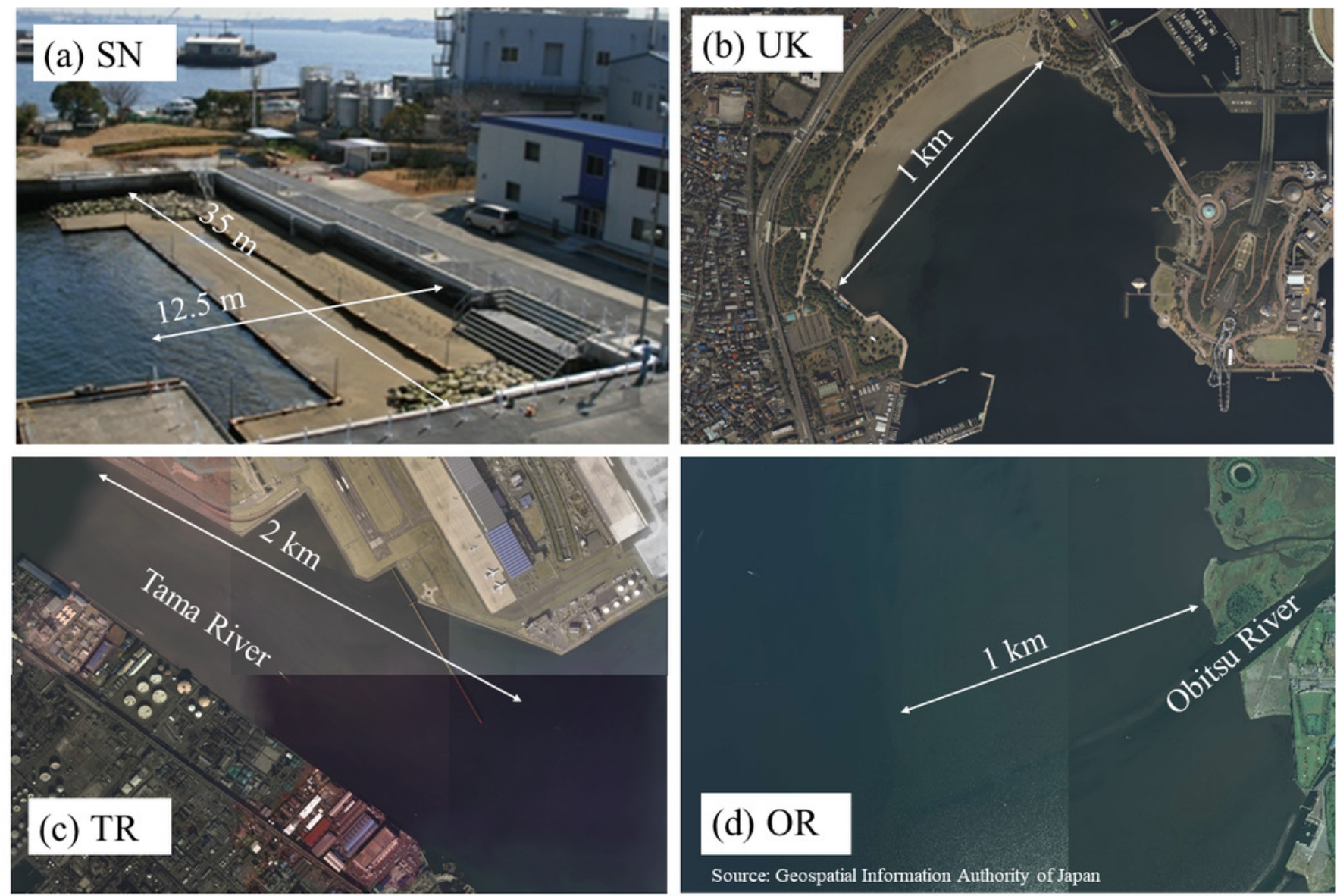
Figure 3 (on next page)

Conceptual model of environmental factors for food provision 


\section{Social System}

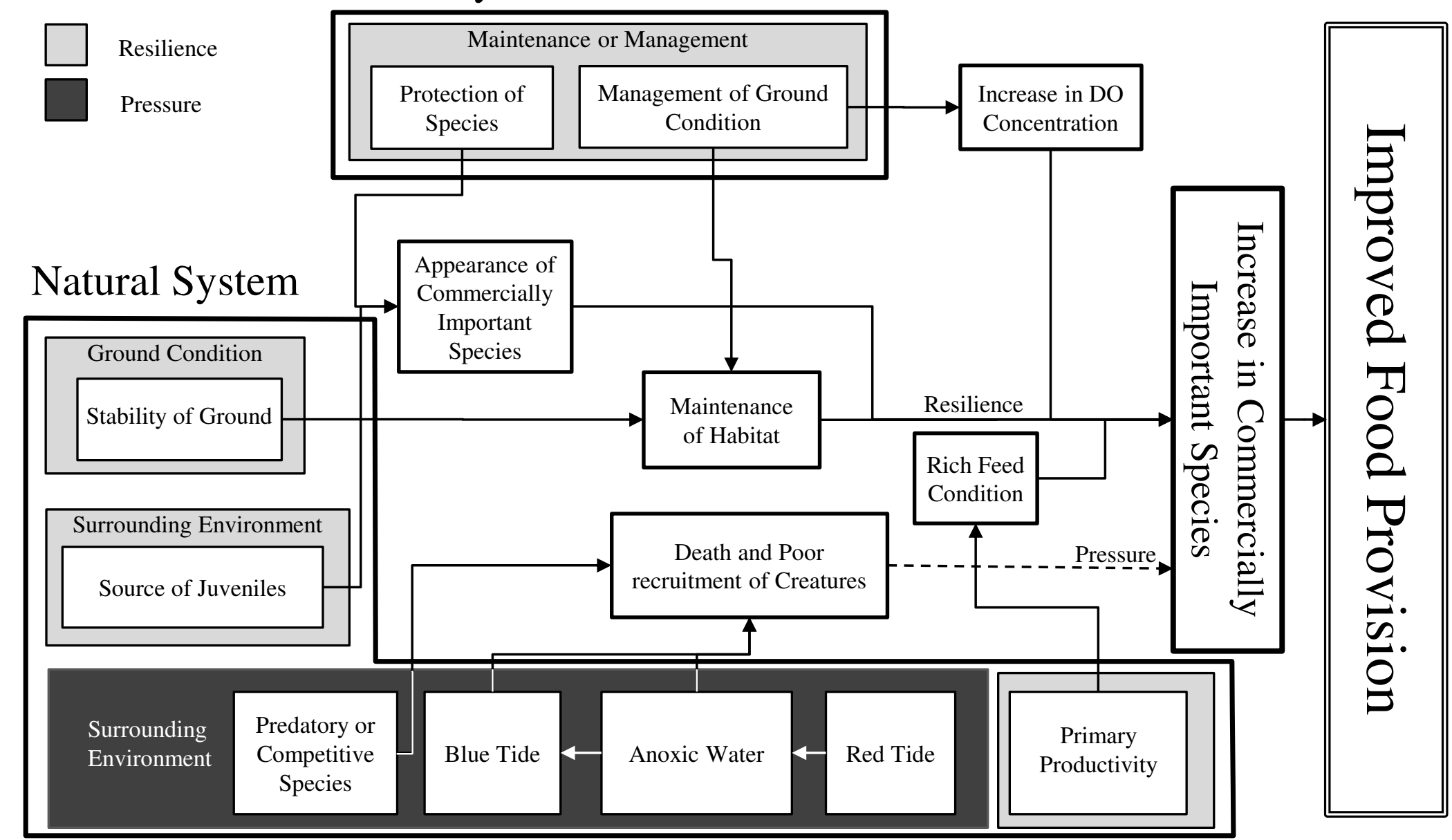


Figure 4 (on next page)

PR score evaluation model for DO concentration 


\section{Figure 5 (on next page)}

\section{Ranges of error in scores}

(A) - (I) trend scores, (J) - (R) likely near-term future status, and (S) - (AA) service scores for food provision, coastal protection, environmental education, research, suspended material removal, organic matter decomposition, carbon storage, degree of diversity, and rare species 


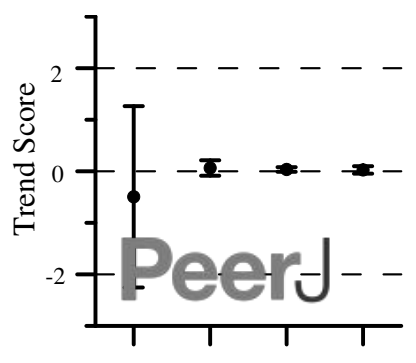

SN UK TR OR

(F) Organic Matter

Decomposition

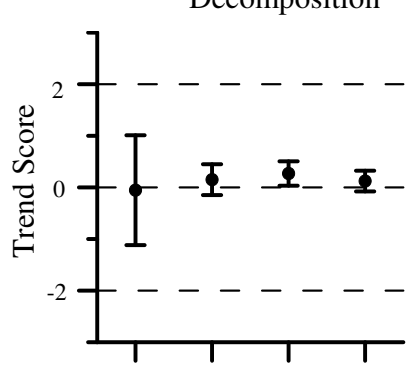

SN UK TR OR

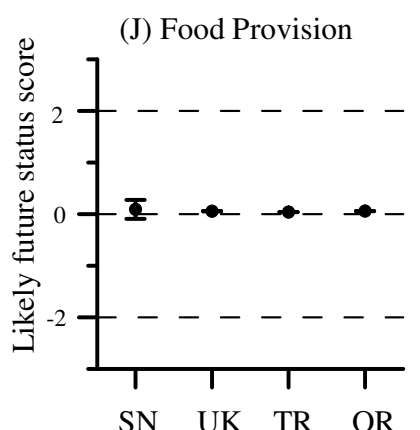

(O) Organic Matter

Decomposition
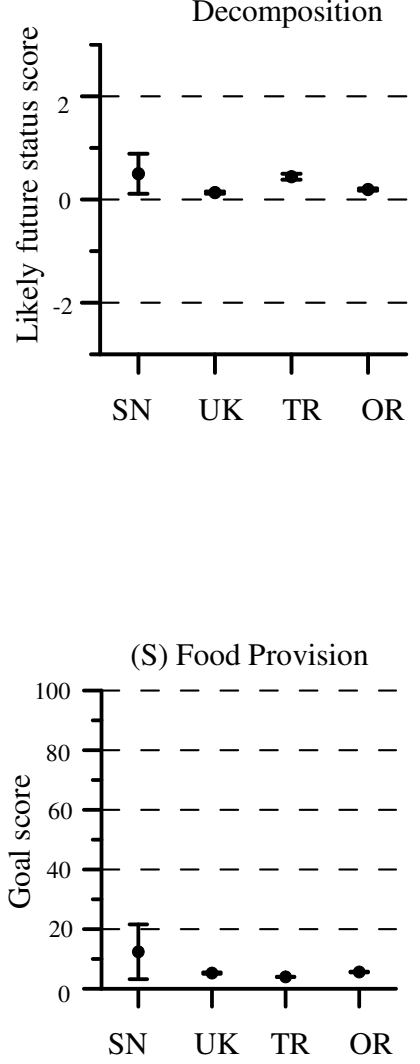

(X) Organic Matter Decomposition
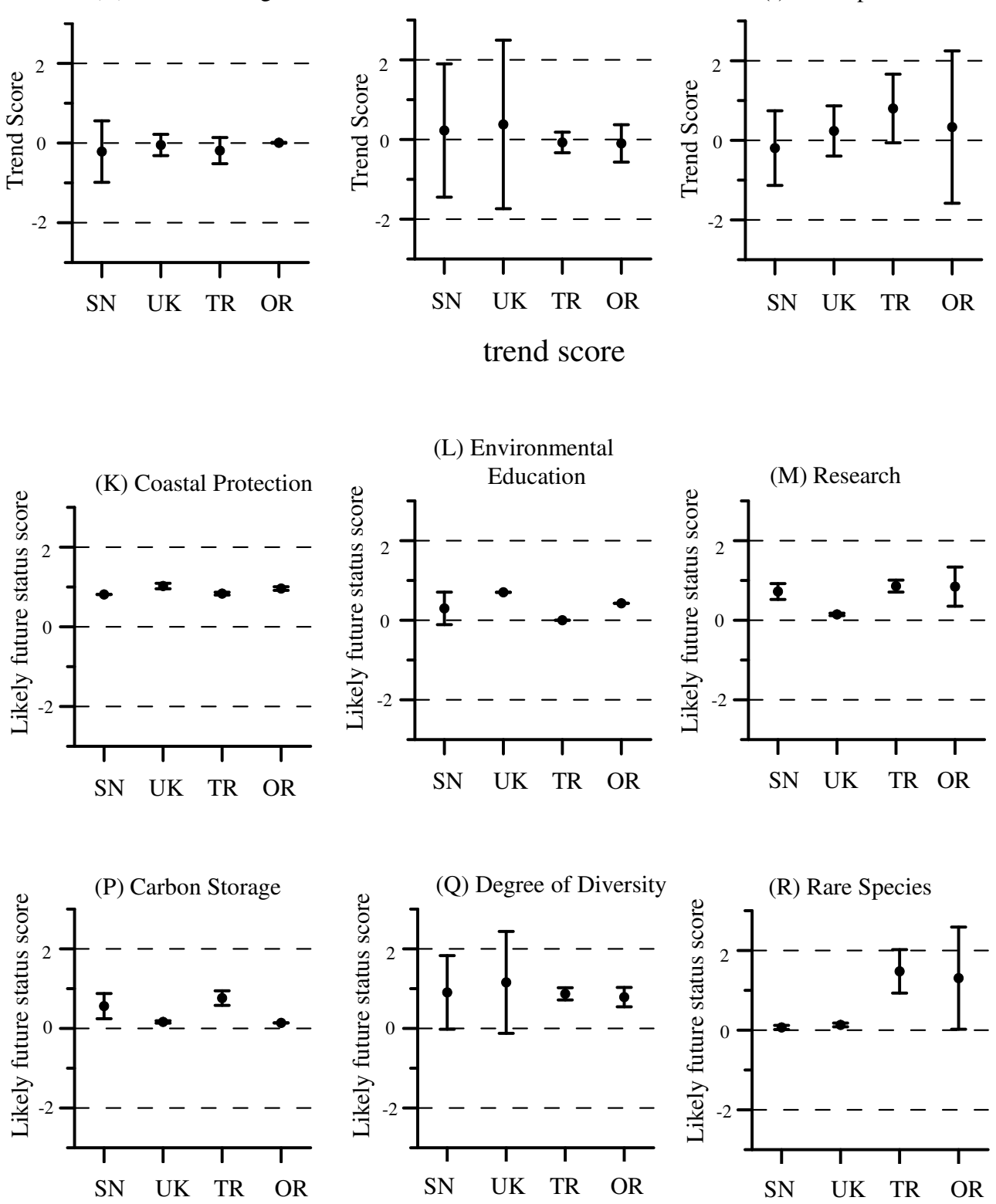

likely near-term future status

(U) Environmental

(T) Coastal Protection
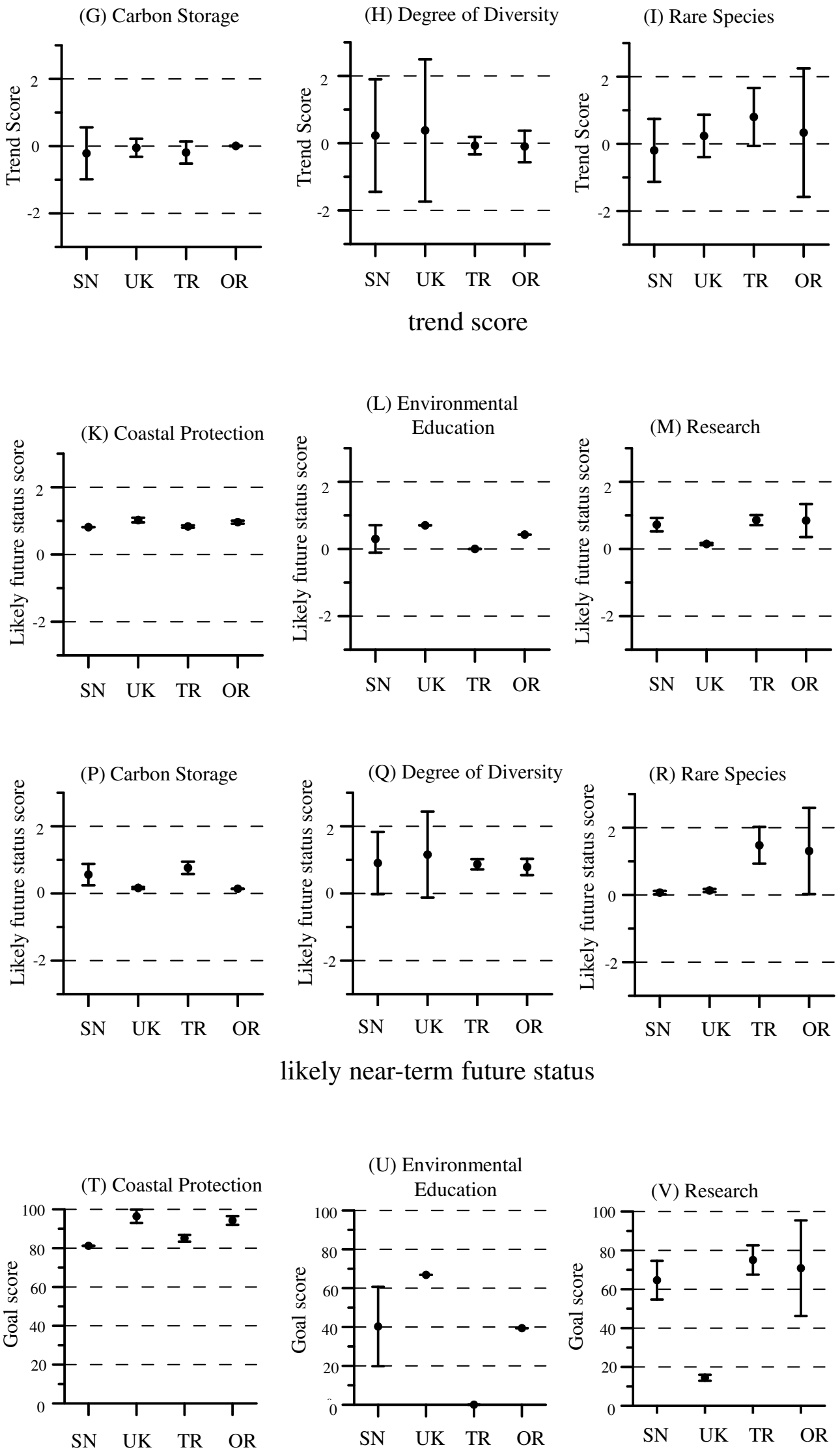

(E) Suspended Material
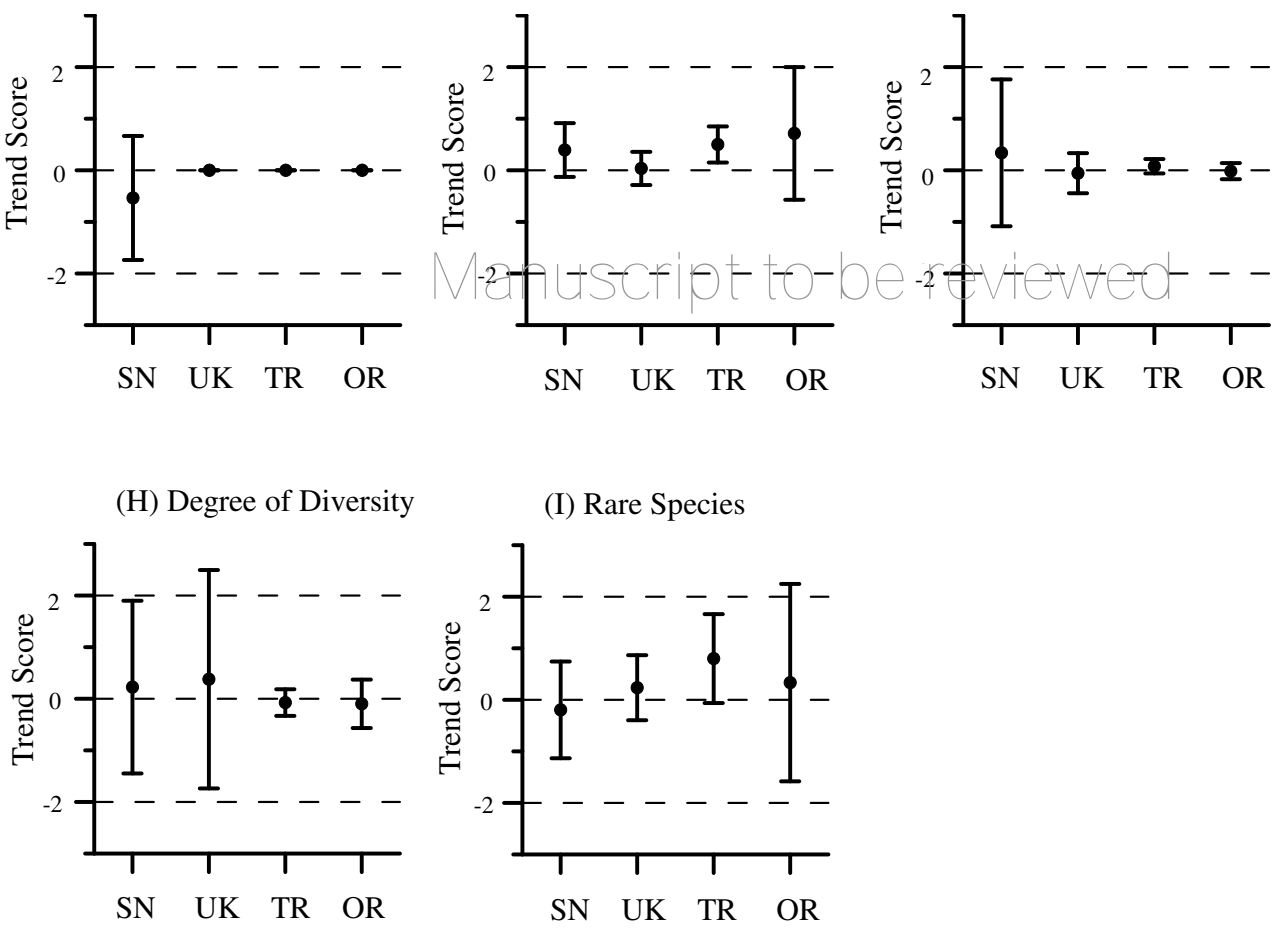

SN UK TR OR
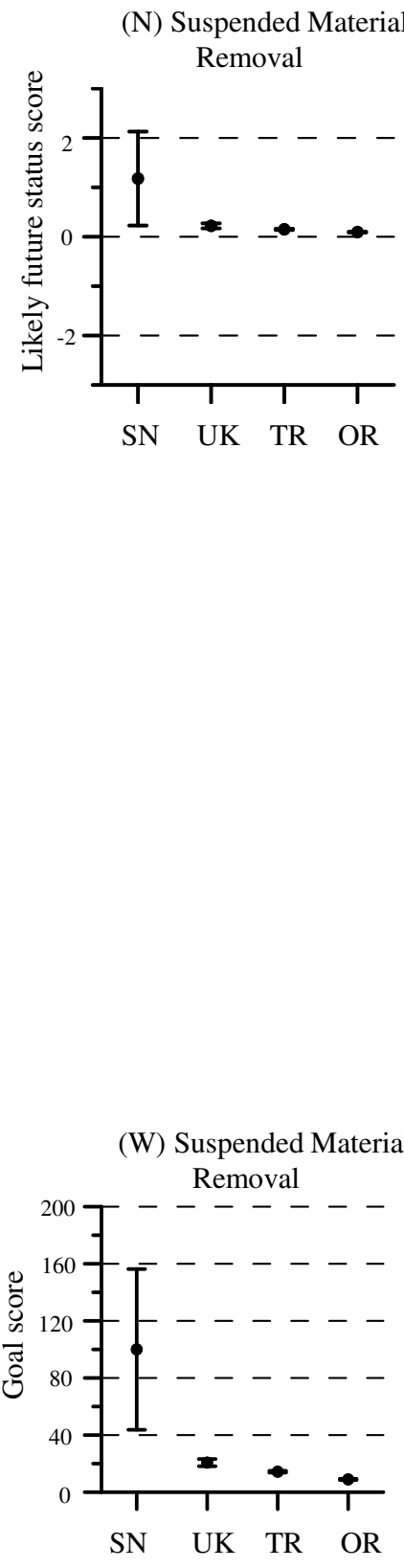

(Y) Carbon Storage

(Z) Degree of Diversity

(AA) Rare Species
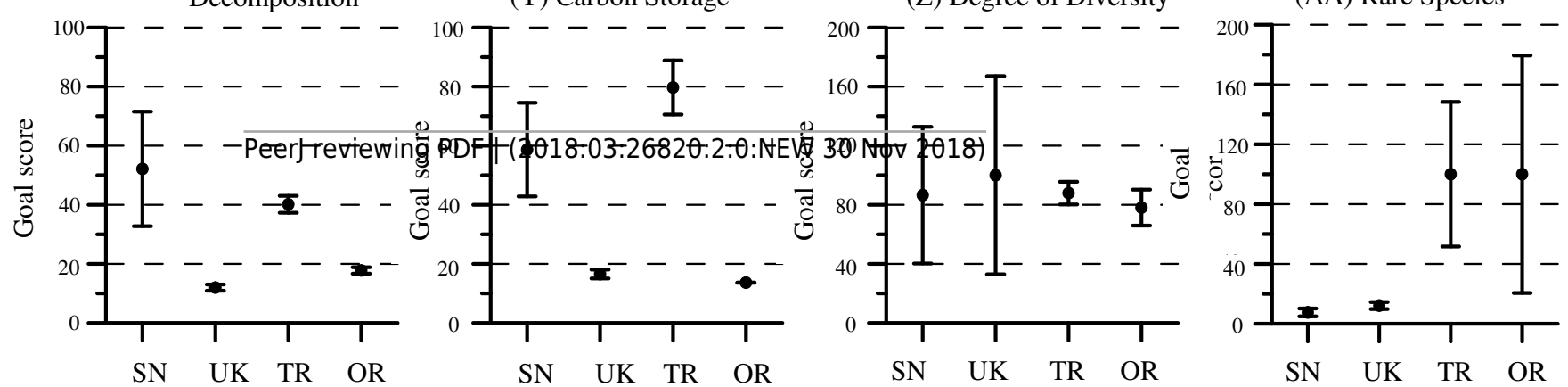

service score 


\section{Table 1 (on next page)}

Characteristics of each evaluated tidal flat in this study 


\begin{tabular}{lllll}
\hline & \multicolumn{1}{c}{$\begin{array}{c}\text { SN } \\
\text { (Shiosai Nagisa) }\end{array}$} & \multicolumn{1}{c}{$\begin{array}{c}\text { UK } \\
\text { (Umi Koen) }\end{array}$} & $\begin{array}{c}\text { TR } \\
\text { (Tama River tidal } \\
\text { flat) }\end{array}$ & $\begin{array}{c}\text { OR } \\
\text { (Obitsu River tidal } \\
\text { flat) }\end{array}$ \\
\hline $\begin{array}{l}\text { Natural or } \\
\text { artificial }\end{array}$ & $\begin{array}{l}\text { Artificial } \\
\text { (completed in }\end{array}$ & $\begin{array}{l}\text { Artificial } \\
\text { (completed in } \\
\text { 1980) }\end{array}$ & Natural & Natural \\
\hline $\begin{array}{l}\text { Sediment } \\
\text { condition }\end{array}$ & Sand & Sand & Sand and mud & Sand and mud \\
\hline Area $\left(\mathrm{m}^{2}\right)$ & 438 & 150,000 & 250,000 & $6,500,000$ \\
\hline Coastline (m) & 35 & 800 & 2500 & 3500 \\
\hline
\end{tabular}

1 


\section{Table 2 (on next page)}

Services, indices of services provided, definitions of spatial and temporal range, and key index unit of tidal flats and tidal flat ecosystems.

The services and indices are described in more detail in the SI. 


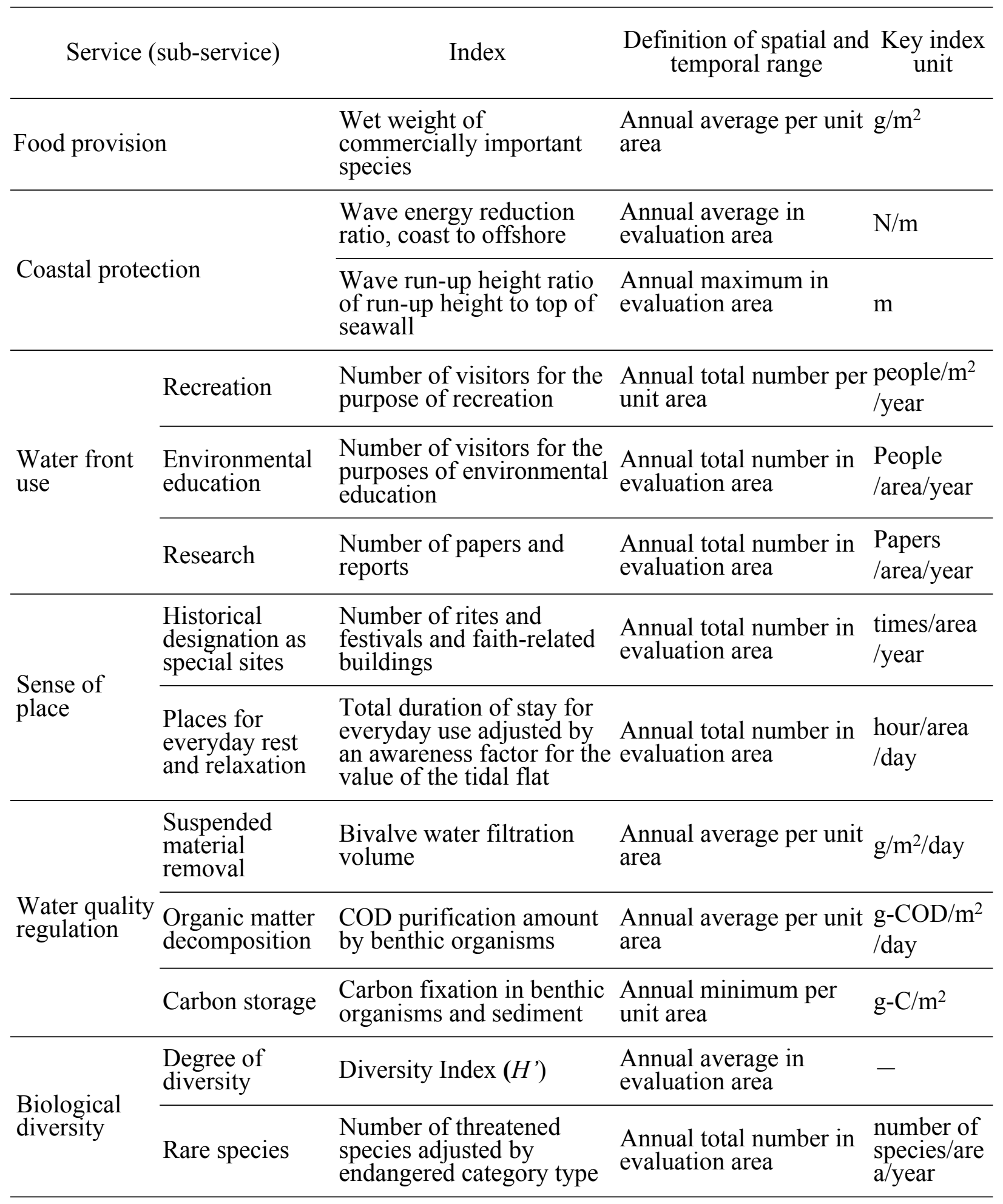




\section{Table 3 (on next page)}

Environmental factors for food provision 
Environmental factor

\begin{tabular}{|c|c|c|}
\hline \multirow{2}{*}{ Anoxic water } & Resilience & DO concentration $>4 \mathrm{mg} / \mathrm{L}$ \\
\hline & Pressure & DO concentration $<4 \mathrm{mg} / \mathrm{L}$ \\
\hline \multirow{2}{*}{ Blue tide } & Resilience & No occurrence of blue tide \\
\hline & Pressure & Occurrence of blue tide \\
\hline \multirow{2}{*}{$\begin{array}{l}\text { Predatory or competitive } \\
\text { species }\end{array}$} & Resilience & $\begin{array}{l}\text { No predatory or competitive species against } \\
\text { commercially important species }\end{array}$ \\
\hline & Pressure & $\begin{array}{l}\text { Existence of predatory or competitive species against } \\
\text { commercially important species }\end{array}$ \\
\hline \multirow{2}{*}{ Primary productivity } & Resilience & Chl-a concentration $>3 \mu \mathrm{g} / \mathrm{L}$ \\
\hline & Pressure & Chl-a concentration $<3 \mu \mathrm{g} / \mathrm{L}$ \\
\hline \multirow[b]{2}{*}{ Stability of ground } & Resilience & Stable ground \\
\hline & Pressure & $\begin{array}{l}\text { Low stability of the ground (erosion, deposition, } \\
\text { consolidation, subsidence, etc.) }\end{array}$ \\
\hline \multirow{2}{*}{ Source of juveniles } & Resilience & Existence of a nearby tidal flat \\
\hline & Pressure & No nearby tidal flat \\
\hline \multirow{2}{*}{$\begin{array}{l}\text { Management of ground } \\
\text { condition }\end{array}$} & Resilience & Existence of management of ground condition \\
\hline & Pressure & $\begin{array}{l}\text { No management of ground condition (e.g., sand fill, } \\
\text { flowing) }\end{array}$ \\
\hline \multirow{2}{*}{ Protection of species } & Resilience & Existence of efforts to protect species \\
\hline & Pressure & No efforts to protect species \\
\hline
\end{tabular}

Pressure or resilience condition

. 


\section{Table 4(on next page)}

Calculated service and sustainability scores for all services.

Gray shading highlights a negative sustainable index score. 


\begin{tabular}{|c|c|c|c|c|c|}
\hline \multirow{2}{*}{\multicolumn{2}{|c|}{ Service (sub-service) }} & \multicolumn{4}{|c|}{ Service score $\left(I_{i}\right)$ / Sustainability score $\left(S_{i}\right)$} \\
\hline & & $\mathrm{SN}$ & UK & TR & OR \\
\hline \multicolumn{2}{|c|}{ Food provision } & $12.4 /-41 \%$ & $5.3 /+17 \%$ & $4.0 /+1 \%$ & $5.6 /+12 \%$ \\
\hline \multicolumn{2}{|c|}{ Coastal protection } & $81.2 / 0 \%$ & $96.4 /+13 \%$ & $85.1 /-4 \%$ & $94.3 /+4 \%$ \\
\hline \multirow{3}{*}{ Water use } & Recreation & $-1-$ & $78.7 /-1 \%$ & $0.3 /-7 \%$ & $0.3 /+16 \%$ \\
\hline & Environmental education & $40.3 /-41 \%$ & $66.8 /+11 \%$ & $0.0 /-$ & $39.4 /+17 \%$ \\
\hline & Research & $64.7 /+26 \%$ & $14.5 /+2 \%$ & $75.1 /+34 \%$ & $70.8 /+48 \%$ \\
\hline \multirow{2}{*}{$\begin{array}{l}\text { Sense of } \\
\text { place }\end{array}$} & $\begin{array}{l}\text { Historical designation as } \\
\text { special sites }\end{array}$ & $-1-$ & $-/-$ & $50.8 /+3 \%$ & $80.0 /+13 \%$ \\
\hline & $\begin{array}{l}\text { Places for everyday rest } \\
\text { and relaxation }\end{array}$ & $-/-$ & $100 /+10 \%$ & $3.2 /-3 \%$ & $2.8 /+17 \%$ \\
\hline \multirow{3}{*}{$\begin{array}{l}\text { Water quality } \\
\text { regulation }\end{array}$} & $\begin{array}{l}\text { Suspended material } \\
\text { removal }\end{array}$ & $100 /+18 \%$ & $20.7 /+13 \%$ & $14.3 /+9 \%$ & $8.9 /+10 \%$ \\
\hline & $\begin{array}{l}\text { Organic matter } \\
\text { decomposition }\end{array}$ & $52.1 /-8 \%$ & $12.0 /+27 \%$ & $40.2 /+22 \%$ & $17.8 /+19 \%$ \\
\hline & Carbon storage & $58.7 /-9 \%$ & $16.6 /-3 \%$ & $79.7 /-8 \%$ & $13.6 /+3 \%$ \\
\hline \multirow{2}{*}{$\begin{array}{l}\text { Biological } \\
\text { diversity }\end{array}$} & Degree of diversity & $86.5 /+10 \%$ & $100 /+28 \%$ & $87.9 /-2 \%$ & $78.1 /+2 \%$ \\
\hline & Rare species & $7.8 /-14 \%$ & $12.0 /+16 \%$ & $100 /+54 \%$ & $100 /+31 \%$ \\
\hline
\end{tabular}

1 Note: A “-" indicates the tidal flat was omitted from the analysis, usually because the service did 2 not apply in that tidal flat. 